AUGMENTIN Brief Summary of Prescribing Information

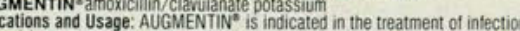
caused by susceptible strains of the designated organisms in the conditions

列 Otitis Media caused by $\beta$-lactamase-producing strains of Branhamella catarnhalis and Hemophilus influenzae.

Sinusitis caused by $\beta$-lactamase-producing strains of Branhamella catarnhals and Hemoghilus inffuenzae

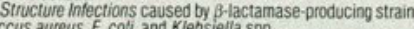
Orinary fract infections caused by $\beta$-lactamase-producing strains of $E$ colli.

Klebsiella spp and Enterabacter Spp.
While AUGMENTIN ${ }^{\circ}$ is indicated only fot the conditions listed above intections caused by ampicillin susceptible organisms are also amenable to AUGMENTIN mpicillin susceptibible organisms and $\beta$-Tactamase-producing organisms susce Bacteriologic studies to determine the causative organisms and their $s$. bility to AUGMENTIN? should be performed together with any indicated surgical

Therapy may be instituted prior to obtaining the results from bacteriologica bility to AUGMERNTIN ${ }^{2}$ when there is reason to believe the infections may involve any of the $\beta$-lactamase-producing organisms listed above. Once the results are known, therapy should be adjusted, if appropriate.

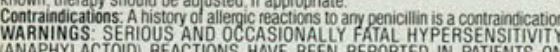
WANAPLACTOID REACTIONS HAVE BEEN REPORTED IN PATIENTS ON PENICILLIN THERAPY ALTHOUGH ANAPHYLAXIS IS MORE FREQUENT FOO
LOWING PARENTERAL THERAPY II HAS OCCURRED IN PATIENTS ON ORAL
PENICILLINS. THESE REACTIONS ARE MORE LIKELY TO OCCUR IN INDIVDD PENICILINS. THESE REACTIONS ARE MORE LIKELY TO OCCUR IN INDIVID
ALS WIIH A HISTORY OF PENICLLLN HYPERSENSITIVIYY AND/OR A HIS
TORY OF SENSITIVITY TO MULTIPLE ALLEREENS. THERE HAVE BEEN REPORT TOAY OF SENSIITVIYY TOMULTIPLEALLERGENS. THERE HAVE BEEN REPORTS
OF INDIVIDUALS WITH A HISTORY OF PENICILLN HYPEASENSITIVITY WHO
HAVE EXPERIENCED SEVERE REACTONS WHEN TREAIED WITH CEPHALO HAVE EXPEAIENCED SEVERE REACTIONS WHEN IREATED WITH CEPHAL
SPORINS. BEEORE INTIIAING THERAPY WITH ANY PENIILILIN, CAREFU
INOUIRY SHOULD BE MADE CONCERNING PREVIOUS HYPEESENSSTIVITY INOUIRY SHOULD BE MADE CONCERNING PAEVIOUS HYPEASENSITIV
REACTIONS TO PENICILINS. CEPHALOSPORINS OR OTHER ALLEFGENS
ANALLERGIC REACTION OCCURS. AUGMENTIN SHOULOBEDISCONTINU ANALLERGIC REACTION OCCUAS AUGMENTIN SHOULD BEDISCONTINUE
AND THE APPROPRIATE THERAPY INSTITUTED SERIOUS ANAPHYLACTO
REACTIONS REOUIRE IMMEDLATE EMERGENCY TREATMENT WITH EPINEP RINE OXYGEN INTRAVENOUS STEROIDS AND ARWAY MANAGEMENT. IN
CLUDING INTUBATION. SHOULD ALSO BE ADMINISTERED AS INDICATED. CLUDING INTUBATION SHOULD ALSO BE ADMINISTERED AS INDICACD
Precautions: General: While AUGMENNIN DOSSESSE the characteristic Iow oxicity of the penicillin group of antibiotics. periodic assessment of organ system functions, including te A high percentage of patients with mononucleosis who receive ampicillin patients with mononucleosi

The possibility of superinfections with mycotic or bacterial pathogens should e kept in mind during therapy If superinfections occur (usually involving
Pseudomonas or Candida). the drug should be discontinued and/or appropriate therapy instituted. Drug / laboratory Test Interactions: Oral administration of AUGMENTIN ${ }^{\circ}$ wil esult in high urine concentrations of amoxicilin. High urine concentrations of mpicillin may result in false positive reactions when testing for the presence of glucose in urine using Clinitest" "Benedicts Solution or Fehing S Solution. Since
this effect may also occur with amoxicillin and therefore AUGMENTIN" it is commended that glucose tests based on enzymatic glucose oxidase reactions

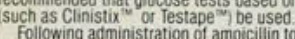

Following administration of ampicillin to pregnant women a transient decrease plasma concentration of totar conjugated estriol, estriol-glucuronide, conju-

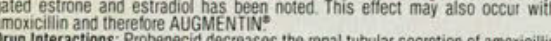
Drug Interactions: Probenecid decreases the renal tubular secretion of amoxicillin Concurrent use with AUGMENTIN ${ }^{2}$ may result in increased and prolonged blood

The concurrent administration of allopurinol and ampicillin increases substan

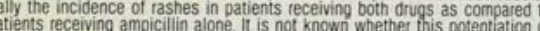
ampicilin rashes is due to allopurinot or the hyperuricemia present in these patients

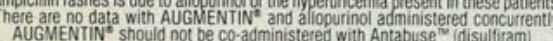
AUGMENTIN ${ }^{2}$ should not be co-administered with Antabuse ${ }^{*}$ idisulfiram).
Carcinogenesis, Mutagenesis, Impairment of fertility: Long-term studies Carcinogenesis. Mutagenesis, Impairment of Fertility. Long-term studies in
animass have not been performed to evaluate carcinogenic or mutagenic potential
Pregnancy (Category B): Reproduction studies have been performed in mice and Pregnancy (Category B: Reproduction studies have been performed in mice and
rats at doses up to ten (io) times the human dose and have revealed no evidence
of impaired fertility or harm to the fetus due to AUGMENTIN" There are, however. no adequate and well-controlled studies in pregnant women. Because animal
reproduction studies are not always predictive of human response, this drug
should be used during pregnancy only if clearly needed.

Should be used during pregnancy only it clearly needed.
Labor and Delivery: Oral ampicilin class antibiotics are generally poorly absorbed Labor and Delivery: Orat ampicilin class antitiotics are generally poorly absorbed
during labot Studies in guinea pigs have shown that intravenous administration
of ampicillin decreased the uterine tone, frequency of contractions, height of of ampicillin decreased the uterine tone, frequency of contractions, height of USe of AUGMENTIN in humans during labor or delivery has immediate or delayed adverse effects on the fetus, prolongs the duration of labor or increases the

Nursing Mothers: Ampicillin class antibiotics are excreted in the milk; therefore.
Nurs caution should be exercised when AUGMENTIN is administered to a nursing woma Adverse Reactions: AUGMENTIN ${ }^{3}$ is generally weil tolerated The majority side effects observed in clinical trials were of a mild and transient nature and less
than $3 \%$ of patients discontinued therapy because of drug related side effect The most frequently reported adverse effects were diarmea/loose stools (9\%),

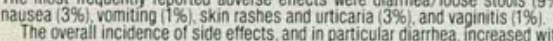
The owerail incidence of side effects, and in particular diarthea, increased with
the higher recommended dose. Other less frequently reported reactions include abdominal discomfort flatulence and headache.
The following adverse reactions have been reported for ampicillin class antibiotics. $\frac{\text { Gastrointestinat Diarnhea, nausea, vomiting. gastritis, stomatitis, glossitis, black }}{\text { haliry tongue, enterocolitis and pseudomembranous colitis. As with some oth }}$ penicilins and some cephalosporins, transient hepatitis and cholestatic jaundice Hypersensitivity reactions: Skin rashes, urticaria, erythema multiforme and an occasional case of extoliative dermatitis have been reported. These reactions may be controlled with antihistamines and, If necessary, Systemic corticosteroids
Whenever such reactions occut the drug should be discontinued, unless the opinion of the physician dictates otherwise. Serious and occasionally fatal hypesensitivity (anaphylactic) reactions can occur with oral penicillin (See Warnings
Liver A moderate rise in SGOT and/or SGPT has been noted in gatients treated Liver A moderate rise in SGOT and/or SGPT has been noted in patients treate
with ampicilin class antibiotics as well as with AUGMENTIN" but the signif cance of these findings is uniknown

hemic and Lymphatic Systems; Anemia, thrombocytopenia, thrombocytopenic herpura, eosinophilia, eukopenia and agranulocytosis have been reported during of therapy and are believed to be hypersensitivity phenomena A slight thrombocytosis was noted in less than $1 \%$ of the patients treated with AUGMEERTIN"
Dosage: Adults: The usual adult dose is one AUGMENTIN 250 tablet every eight hours. For more severe infections and infections of the respiratory tract, the

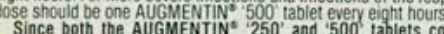
Since both the AUGMENTIN
ount of clavulanic acid $125 \mathrm{I}^{*}$ ' and ' $500^{\prime}$ tablets contain the same potassium salt, two AUGMENTIN A
AGMENTIN $500^{\prime}$ tablet for treatment of more severe infections.

\section{Causes of sudden death in cocaine abusers}

Underlying disease (fixed coronary artery disease, cerebral aneurysm, atrioventricular malformation) or massive drug overdose are the primary causes of sudden death in cocaine addicts.

Overdose usually occurs via "body packing" or "body stuffing." The former method refers to carrying cocaine stored in an ingested latex packet. Rupture comes about during normal travel through the gastrointestinal tract. Toxicity follows.

In body stuffing the user ingests large quantities of the agent in order to avoid police arrest. Overdose symptoms are often delayed. Meanwhile, radiographs prove ineffective in this instance. However, they are useful prior to surgical removal of drugs in body packing cases.

Careful monitoring of the patient's cardiopulmonary system is essential in any treatment regimen. Generally, thiamine, $50 \%$ dextrose and naloxone are given, along with gastric lavage. Charcoal and a cathartic agents are then inserted. Psychiatric followup should be considered as part of any treatment regimen.

Drug overdose via body stuffing should be suspected of any person presenting with acute psychosis and deterioration. Treatment should commence accordingly.

Garber MW, Flaherty D: Cocaine and sudden death. Amer Fam Prac 1987;36:227-230.

\section{Single-dose therapy in urinary tract infections}

A single dose of antimicrobial agents, the new norfloxacin among them, is just as effective in treating common urinary tract infections as the more conventional 7 to 10 day treatment. Likewise, such antibiotics administered in low doses over at least a 6 -week period are usually sufficient to supress recurrent bacteriuria.

However, men, pregnant women, and patients with renal failure or urinary tract abnormalities are not suitable candidates for single-dose treatment. Rather, a urine culture and antimicrobial susceptibility testing should precede traditional therapy in these patients.

When single-dose therapy fails, upper tract infection may be present. In this case, the aforementioned regimen should be followed.

Wilhelm MP, Edson RS: Antimicrobial agents in urinary tract infections. Mayo Clin Proc 1987;62:1025-1031.

\section{Managing obstructive sleep apnea}

The incidence of obstructive sleep apnea increases with age, particularly among obese men. Apnea, which is defined as inhibited breathing for 10 seconds or more, is attributed to blocked air flow at the oronasopharyngeal site.

No specific guidelines exist as to when treatment should commence. However, persons experiencing more than 30 obstructive apneas per hour of sleep as well as those with frequent and severe incidents of oxygen desaturation should seriously be considered for one management approach or another.

Therapeutic options include tracheostomy, surgery, weight loss, nasal continuous positive airway pressure, and uvulopalatopharyngoplasty. Each has advantages and disadvantages.

While tracheostomy provides uniform relief from this disorder, the procedure itself can prove difficult, especially with obese patients. The 


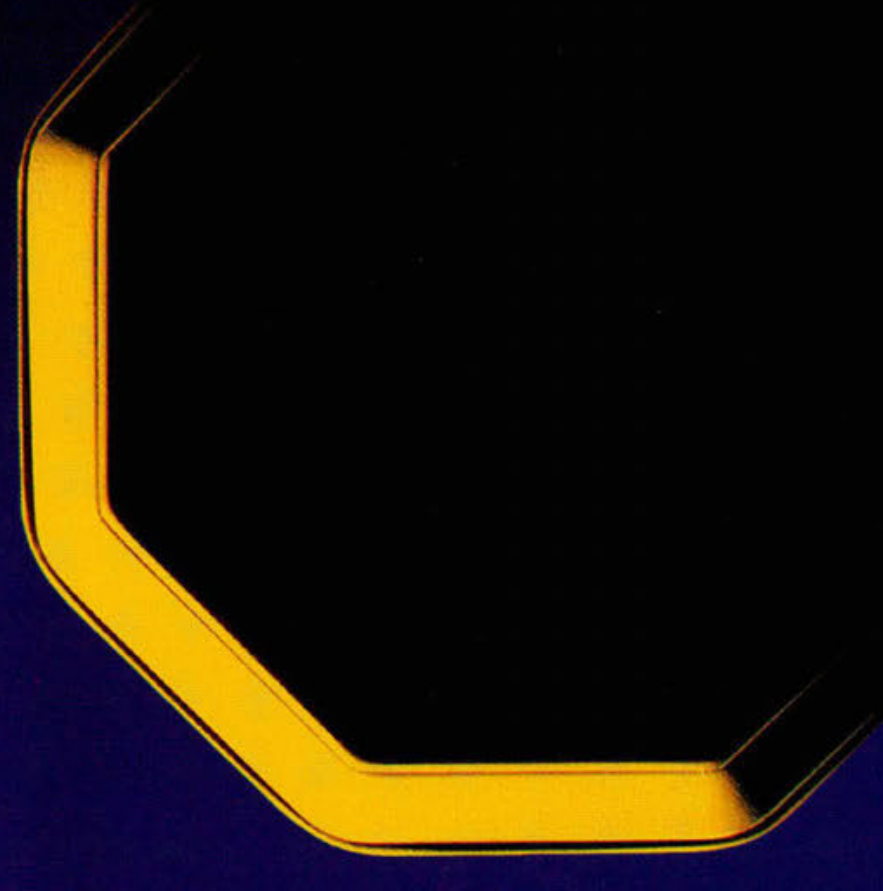

New from Merck Sharp \& Dohme

\section{Now you can act decisively against elevated cholesterol}




\section{Introducing

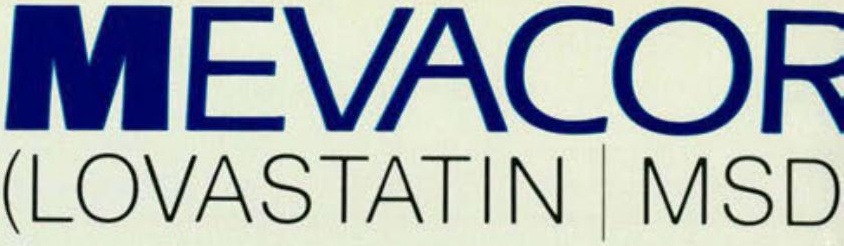

MEVACOR is indicated as an adjur to diet for the reduction of elevated tot and LDL cholesterol levels in patien with primary hypercholesterolem (Types IIa and IIb) when response nonpharmacologic measures has be inadequate.

MEVACOR is contraindicated in patien hypersensitive to any component of tt medication; in patients with active liver disea or unexplained persistent transaminas elevations; in pregnant or lactating patient and in women of childbearing age, exce when such patients are highly unlikely conceive.

The effect of lovastatin-induced changes serum lipoprotein levels, including reduction serum cholesterol, on cardiovascular morbidi or mortality has not been establishec

For a Brief Summary of Prescribin Information, please see last page of thi advertisement.

Remarkable efficacy in clinical studies:

This graph is a symbolic

representation of the response

to MEVACOR over lime. A

substantial response was seen

within 2 weeks, and the

maximum therapeutic

response occurred within

\section{WEEKS}

4 to 6 weeks. 


\section{Selected Cautionary Information}

Liver Dysfunction: Marked persistent increases (to more than 3 times the upper limit of normal) in serum transaminases occurred in $1.9 \%$ of adult patients who received lovastatin for at least one year. It is recommended that liver function tests be performed every 4 to 6 weeks during the first 15 months of therapy and periodically thereafter in all patients. In patients who develop elevated transaminase levels, measurements should be repeated promptly and performed more frequently. If the transaminase levels show evidence of progression, particularly if they rise to 3 times the upper limit of normal and are persistent, the drug should be discontinued.
Skeletal Muscle: Myositis has reported in approximately $0.5 \%$ of pati and should be considered in any patient diffuse myalgias, muscle tenderness, anc marked elevation of CPK. Patients shoul advised to report promptly unexplai muscle pain or tenderness, particularl accompanied by malaise or fever. Ther with MEVACOR ${ }^{\star}$ (Lovastatin, MSD) shc be discontinued if markedly elevated levels occur or myositis is diagnosed.

Consideration should be given temporarily withholding discontinuing drug therapy in patient with a risk factor predispos to the development of renal fail secondary to rhabdomyolysis.

Eye: During trials with MEVACOR, lenticular opacities were noted and SC opacities seen at baseline were not note the final examination; the overall prevale of opacities did not increase and there no clinically significant change in vis acuity in the patients who had new opaci reported. A causal relationship of lovast to these findings has not been establist Nevertheless, until further experience obtained, a slit lamp examination recommended before or shortly at initiation of treatment with MEVACOR annually thereafter. 
For most patients

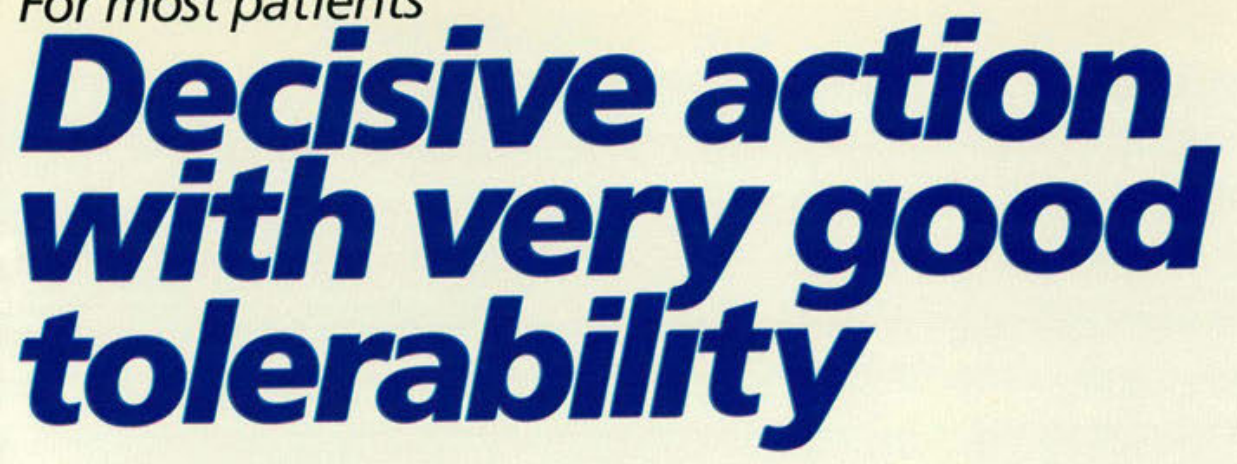

- In clinical studies, MEVACOR was generally well tolerated. Side effects were usually mild and transient

- About $2 \%$ discontinued about $2 \%$ of patients in controlled and uncontrolled studies were discontinued from therapy due to drug-related adverse events

\section{- Concomitant use with} other drugs-in clinical trials, no clinically significant adverse interactions were seen with

- digoxin - cholestyramine

- warfarin - calcium channel

- beta blockers

blockers - NSAIDs

- diuretics

Most of the patients who have developed myositis were receiving concomitant therapy with immunosuppressive drugs or gemfibrozil. Therefore, the benefits and risks of using lovastatin concomitantly with immunosuppressive or fibrate drugs should be carefully considered (see WARNINGS, Skeletal Muscle, in the Brief Summary of Prescribing Information).

\begin{tabular}{|l|l|c|c|}
\hline \multicolumn{6}{|c|}{ Compare gastrointestinal side effects that occurred } \\
in controlled studies ranging from 12 to 22 weeks
\end{tabular}

Muscle cramps $(1.1 \%)$, myalgia $(2.4 \%)$, dizziness $(2.0 \%)$, headache $(9.3 \%)$, rash/pruritus $(5.2 \%)$, blurred vision $(1.5 \%)$, and dysgeusia $(0.8 \%)$ were also reported with MEVACOR in controlled studies.

Range of dosages: MEVACOR 5 to $40 \mathrm{mg}$ b.i.d., cholestyramine 4 to $12 \mathrm{~g}$ b.i.d., probucol 500 mg b.i.d.

For a Brief Summary of Prescribing Information, please see last page of this advertisement.

\section{Take action with} new
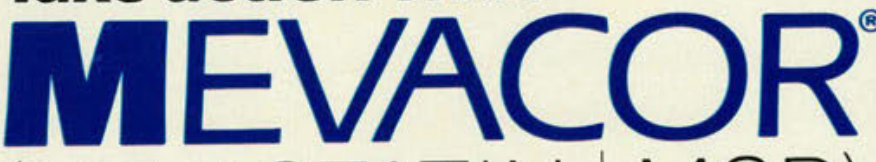

(LOVASTATIN MSD)

$20 \mathrm{mg}$ in appropriate patients 
MEVACOR* (Lovastatin, MSD) is indicated as an adjunct to diet for the reduction of elevated total and LDL cholesterol levels in patients with primary hypercholesterolemia (Types IIa and IIb) when response to nonpharmacologic measures has been inadequate.

It should ideally be determined that patients for whom treatment with MEVACOR is being considered have an elevated LDL cholesterol level as the cause for an elevated serum cholesterol.

Cholesterol levels should be monitored periodically and consideration should be given to reducing the dosage of MEVACOR if cholesterol levels fall below the targeted range. 


\section{Decisive action with once- or twice- a-day dosing}

\section{Recommended starting dose:} $20 \mathbf{~ m g}$ with the evening meal

- Patients should be continued on a standard cholesterol-lowering diet

- Prescribe with the evening meal

- Patients with severely elevated serum cholesterol (i.e., $>300 \mathrm{mg} /$ $\mathrm{dL}$ on diet) may be started at $40 \mathrm{mg} /$ day

- Wait at least 4 weeks between dosage adjustments

- Patients should be titrated to an individualized dosage and dose schedule

For a Brief Summary of Prescribing Information, please see following page.

\begin{tabular}{|c|l|c|c|c|}
\hline \multicolumn{6}{|c|}{ Response is schedule dependent and dose dependent } \\
\hline $\begin{array}{c}\text { Daily } \\
\text { Dosage }\end{array}$ & Schedule & Total-C & LDL-C & HDL-C \\
\hline $20 \mathrm{mg}$ & $20 \mathrm{mg}$ once a day & $-17 \%$ & $-21 \%$ & $+11 \%$ \\
\hline \multirow{2}{*}{$40 \mathrm{mg}$} & $2 \times 20 \mathrm{mg}$ once a day & $-24 \%$ & $-28 \%$ & $+8 \%$ \\
\cline { 2 - 5 } & $20 \mathrm{mg}$ b.i.d. & $-27 \%$ & $-32 \%$ & $+10 \%$ \\
\hline \multirow{2}{*}{$80 \mathrm{mg}$} & $4 \times 20$ mg once a day & $-30 \%$ & $-37 \%$ & $+11 \%$ \\
\cline { 2 - 5 } & $2 \times 20$ mg b.i.d. & $-33 \%$ & $-41 \%$ & $+9 \%$ \\
\hline
\end{tabular}

Four controlled multicenter studies: mean change from baseline

(P) For more information about cholesterol, call the Cholesterol InfoLine for Physicians 1-800-MD-GOALS

A professional service of Merck Sharp \& Dohme

\section{Take action with}
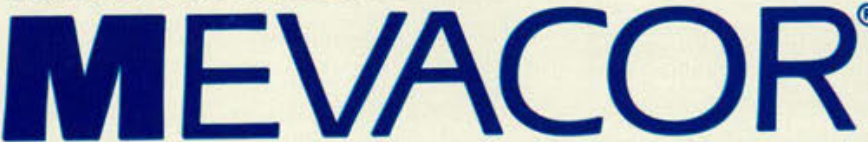

(LOVASTATIN

MSD)

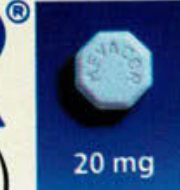

in appropriate patients 


\section{new

MEVACOR

MEVACOR*

(Lovastatin | MSD)

CONTRAINDICATIONS

Hypersensitivity to any component of this medication.

Active liver disease or unexplained persistent elevations of serum transaminases.

Pregnancy and lactation

Alheriscontinuation of lipidlowering drugs during pregnancy should have little impact on the outcom terol and - other prapy of primary hypercholesterolemia. Moreover, cholestial components for fetal development, including synthesis of steroids and
tial cell membranes. Because of the ability of inhibitors of HMG-COA reduc. tase such as MEVACOR to decrease the synthesis of cholesterol and possibly other products of the cholesterol biosynthesis pathway. MEVACOR may cause fetal harm when administered to a pregnan woman. Therefore, lovastatin is contraindicated during pregnancy. Lovastatin should be administered to women of childbearing age onh when such patients are highly unlikely to conceive. If the patient becomes pregnant while taking this drug, lovastatin should be discontinuect patient should be apprised of the potential hazard to the fetus.

\section{WARNINGS}

Marked persistent increases (to more than 3 times the upper limit of normal) in serum transaminases occurred in $1.9 \%$ of adult patients who received lovastatin for at least one year (see ADVERSE REACTIONS). When the drug was interrupted or discontinued in these patients. the transaminase levels usually fell slowly to pretreatment levels. The increases usually appeared 3 to 12 months after the start of therapy with lovastatin and were not associated with jaundice or other clinical signs or symptoms. There was no evidence of hypersensitivity. A liver biopsy was done in one of these patients and showed areas of focal hepatitis. In this patient, transaminase levels returned to normal following discontinuation of therapy. Some of these patients had abnormal liver function tests prior to lovastatin therapy and/or consumed substantial quantities of alcohol. It is recommended that liver function tests be performed every 4 to 6 weeks during the first 15 months of therapy with lovastatin and patients who develop elevated serum transaminase levels, and in these patients who develop elevated serum transaminase levels, and in these more frequently. If the transaminase levels show evidence of progression. particularly if they rise to 3 times the upper limit of normal and are particularly if they rise to 3 times the upper limit of normal and are
persistent, the drug should be discontinued. Liver biopsy should be considered if elevations are persistent beyond the discontinuation of the drug. The drug should be used with caution in patients who consume sub. stantial quantities of alcohol and/or have a past history of liver disease Active liver disease or unexplained transaminase elevations are contraindications to the use of lovastatin.

As with other lipid-lowering agents, moderate (less than 3 times the reported following therapy with MEVACOR (see ADVERSE REACTIONS) These changes appeared soon after initiation of therapy with MEVACOR. were often transient, were not accompanied by any symptoms, and interruption of treatment was not required.

Skeletal Muscle

Myalgia has been associated with lovastatin therapy. Transient, mildly elevated creatine phosphokinase levels are commonly seen in lovastatintreated patients. However, in clinical trials. approximately $0.5 \%$ of patients developed myositis, 1.e., myalgia associated with markedly elevated CPK levels. In cardiac transplant patients who were receiving immunosup. pressive drugs including cyclosporine, there have been reports of severe thabdomyolysis that precipitated acute renal failure. Myositis should be considered in any patient with diffuse myalgias. muscle tenderness. and/or marked elevation of CPK. Patients should be advised to report promptly unexplained muscle pain or tenderness, particularly if accom. panied by malaise or fever. Lovastatin therapy should be discontinued if markedly elevated CPK levels occur or myositis is diagnosed

Most of the patients who have developed myositis were receiving concomitant therapy with immunosuppressive drugs or gemfibrozil. In clinical trials, about 30 percent of patients on immunosuppressive therapy including cyclosporine developed myositis within a year after starting lovastatin; the corresponding value for gemfibrozil was approximately 5 percent. It is not known whether the same phenomenon occurs with other fibrates. Therefore, the benefits and risks of using lovastatin con-
comitantly with immunosuppressive or fibrate drugs should be carefully
considered.

Consideration should be given to temporarily withholding or discontinuing drug therapy in any patient with a risk factor predisposing to the development of renal failure secondary to rhabdomyolysis, including: severe acute infection, hypotension, major surgery, trauma, severe metabolic, endocrine, or electrolyte disorders, and uncontrolled seizures. PRECAUTIONS

Before instituting therapy with MEVACOR, an attempt should be made

Before instituting therapy with MEVACOR, an attempt should be made
to control hypercholesterolemia with appropriate diet, exercise, weight to control hypercholesterolemia with appropriate diet, exercise, weight
reduction in obese patients, and to treat other underlying medical probreduction in obese patients, and to treat
lems (see INDICATIONS AND USAGE).

Eye

There was a high prevalence of baseline lenticular opacities in the patient population included in the clinical trials with lovastatin. During these trials the appearance of new opacities was noted. The caus relationship of lovastatin to these findings has not been established. Of 431 patients examined with slit lamp at baseline and during therapy with lovastatin, 34 had opacities reported at the final examination ( 5 to 15 months after starting lovastatin) that were not noted at baseline. On the at the final examination, so that the prevalence did not increase. There was no clinically significant change in visual acuity in the patients who had new opacities reported, nor was any patient, including those with opacities noted at baseline, discontinued from therapy because of a decrease in visual acuity. Nevertheless, until further experience is obtained, it is recom mended that patients placed on lovastatin therapy be examined with a sit lamp before or shortly after initiation of treatment and annually thereatter.
MEVACOR*

(Lovastatin | MSD)

Homozygous familial Hypercholesterolemia
MEVACOR is less ffective in hypercholesterolemia. possibly because these patients have no functiona $\mathrm{LDL}$ receptors. MEVACOR appears to be more likely to raise serum trans aminases (see ADVERSE REACTIONS) in these homozygous patients. Drug Interactions

Muscle.

Antipyrine: Antipyrine is a model for drugs metabolized by the microsomal hepatic enzyme system (cytochrome P450 system). Because lovastatin had no effect on the pharmacokinetics of antipyrine, interactions with other drugs metabolized via this mechanism are not expected. Propranolol: In normal volunteers, there was no clinically significan pharmacokinetic or pharmacodynamic interaction with concomitant ad ministration of single doses of lovastatin and propranolo.

Digoxin: In patients with hypercholesterolemia concomitant admin. istration of lovastatin and digoxin resulted in no effect on digoxin plasm concentrations.

Warlarin: The concomitant administration of lovastatin and warfarin to a tew patients with hypercholesterolemia did not suggest an alteration the anticoagulant action of warfarin.

Other Concomitant Therapy: Although specific interaction studies were not performed, in clinical studies, lovastatin was used concomitantly with inflammatory drugs (NSAIDs) without evidence of clinically significant adverse interactions.

Drug/Laboratory Test Interactions

Lovastatin may elevate creatine phosphokinase and transaminase lev els (see ADVERSE REACTIONS). This should be considered in the differential diagnosis of chest pain in a patient on therapy with lovastatin.

Carcinogenesis. Mutagenesis, Impairment of Fertility

In a 21-month carcinogenic study in mice, a statistically significant $(p<0.05)$ increase in the incidence of hepatocellular carcinomas and adenomas was observed at doses of $500 \mathrm{mg} / \mathrm{kg} / \mathrm{day}$ ( 312 times the maximum recommended human dose) of lovastatin. These changes were not seen in mice given doses of 20 and $100 \mathrm{mg} / \mathrm{kg} /$ day (12.5 and 62.5 times the maximum recommended human dose)

A statistically significant increase $(p \leq 0.05)$ in the incidence of puimonary adenomas was seen in female mice receiving $500 \mathrm{mg} / \mathrm{kg} /$ day ( 312 imes the maximum recommended human dose): no similar changes were seen in males at any dose or in females receiving 20 or 100 $\mathrm{mg} / \mathrm{kg} / \mathrm{day}$ ( 12.5 or 62.5 times the maximum recommended human dose). Because the incidence of pulmonary tumors was within the range of untreated animals in studies of similar duration, the relationship of this latter change to treatment is not known.

In addition, an increase in the incidence of papilloma in the non glandular mucosa of the stomach was observed in mice receiving 100 and $00 \mathrm{mg} / \mathrm{kg} /$ day ( 62.5 and 312 times the maximum recommended human dose); no increase was seen at a dosage of $20 \mathrm{mg} / \mathrm{kg} / \mathrm{day}$ (12.5 times the maximum recommended human dose). The glandular mucosa was not antected. The human stomach contains only glandular mucosa. Importantly, there is a strong association between this change and hyperplasia characteristic treated with HMG-COA reductase inhibitors and is most probably a result of inhibition of the reductase in this tissue.

Similar squamous epithelium is found in the esophagus and anorectal junction of the mouse and rat: however. no evidence of a similar drug. induced hyperplastic response was observed in these tissues in studies of up to 21 months in the mouse given up to $500 \mathrm{mg} / \mathrm{kg} / \mathrm{day}$ ( 312 times the maximum recommended human dose). or in a study of 24 months in the rat given $180 \mathrm{mg} / \mathrm{kg} /$ day (112 times the maximum recommended human dose).

In a 24-month carcinogenicity study in rats, there was a positive dose esponse relationship for hepatocellular carcinogenicity in males (unadasted $p=0.025$ ). However, because the incidence or hepatocellular carcispontaneously in this strain of rat, the implications of this finding are uncleat.

No evidence of mutagenicity was observed in a microbial mutagen test using mutant strains of Salmonella typhimurium with or without rat or using mutant strains of Salmonella typhimurium with or without rat or
mouse liver metabolic activation. In addition, no evidence of damage to genetic material was noted in an in vitro alkaline elution assay using rat or mouse hepatocytes, a V-79 mammalian cell forward mutation study, an in vitro chromosome aberration study in CHO cells, or an in vivo chro-

No drug-related effects on fertility were found in studies with rats.

\section{Pregnancy}

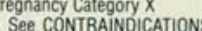

Lovastatin has been shown to produce skeletal malformations in the rat fetus at doses of $800 \mathrm{mg} / \mathrm{kg} / \mathrm{day}$ ( 500 times the maximum recommended human dose). At similar doses in mice, an increase in skeletal malformations was observed. These individual changes are within the range of those observed spontaneously in this strain of mouse. No drug-induced changes were seen in either species at doses of up to $80 \mathrm{mg} / \mathrm{kg} / \mathrm{day} / 50$ times the maximum recommended human dose). No evidence of malformations was noted in rabbits at up to $15 \mathrm{mg} / \mathrm{kg} /$ day (highest tolerated dose-about 9 times the maximum recommended human dose). There are no data in pregnant women.

Nursing Mothers

Studies in rats have shown that lovastatin is excreted in the milk. It is not known whether this drug is excreted in human milk. Because many drugs are excreted in human milk and because of the potential for serious adverse reactions in nursing infants from MEVACOR, women taking
lovastatin should not nurse their intants (see CONTRAINDICATIONS)

Pediatric Use

Safety and effectiveness in children have not been established. Because children are not likely to benefit from cholesterol lowering for at least a decade and because experience with this drug is limited (no studies in
MEVACOR*

(Lovastatin MSD)

subjects below the age of 20 years), treatment of children with lovastatin ADVERSE REACTIONS

MEVACOR is generally well tolerated; adverse reactions usually hav been mild and transient. Less than $1 \%$ of patients were discontinued fron controlled clinical studies due to adverse experiences attributable t MEVACOR. About $2 \%$ of patients were discontinued from all studie MEVACOR; about one-third of these patients were discontinued due increases in serum transaminases.

Clinical Adverse Experiences

Adverse experiences reported in patients treated with MEVACOR Adverse experiences reported in patients treated $\mathrm{w}$
controlled clinical studies are shown in the table below:

\begin{tabular}{|c|c|c|c|c|}
\hline & $\begin{array}{c}\text { MEVACOR } \\
(\mathrm{N}=613) \\
\%\end{array}$ & $\begin{array}{c}\text { Placebo } \\
(\mathrm{N}=82) \\
\%\end{array}$ & $\begin{array}{c}\text { Cholestyramine } \\
(\mathrm{N}=88) \\
\%\end{array}$ & $\begin{array}{c}\begin{array}{c}\text { Probucc } \\
(\mathrm{N}=97 \\
\%\end{array} \\
\end{array}$ \\
\hline \multirow{5}{*}{$\begin{array}{l}\text { Gastrointestinal } \\
\text { Constipation } \\
\text { Diarrnea } \\
\text { Dyspepsia } \\
\text { Flatus } \\
\text { Abdominal pain/cramps } \\
\text { Heartburn } \\
\text { Nausea }\end{array}$} & 4.9 & & & \\
\hline & 55 & 4.9 & & \\
\hline & $\begin{array}{l}3.9 \\
6.4\end{array}$ & 2.4 & $\begin{array}{l}13.6 \\
21.6\end{array}$ & \\
\hline & 5.7 & 2.4 & & 5 \\
\hline & & 37 & & 6 \\
\hline \multirow{4}{*}{$\begin{array}{l}\text { Musculoskeletal } \\
\text { Muscle cramps } \\
\text { Myagia } \\
\text { Nervous System/Psychiatric } \\
\text { Dizziness } \\
\text { Headache } \\
\text { Skin }\end{array}$} & & & & \\
\hline & $\begin{array}{l}1.1 \\
2.4\end{array}$ & $\overline{12}$ & 1.1 & \\
\hline & & & & \\
\hline & & $\begin{array}{l}1.2 \\
4.9\end{array}$ & $\overline{4.5}$ & \\
\hline \multirow{2}{*}{$\begin{array}{l}\text { Rash/pruritus } \\
\text { Special Senses } \\
\text { Blurred vision } \\
\text { Dysgeusia }\end{array}$} & 5.2 & - & 4.5 & - \\
\hline & $\begin{array}{l}1.5 \\
0.8\end{array}$ & $I$ & $\begin{array}{l}1.1 \\
1.1\end{array}$ & 3.1 \\
\hline
\end{tabular}

aboratory Tests

Marked persistent increases of serum transaminases have been note

About $11 \%$ of patients had elevations of creatine phosphokinase (CPK levels of at least twice the normal value on one or more occasions. Th cerresponding values tor the control agents were cholestyramine. percent and probucol, 2 percent. This was attributable to the noncardiac raction of CPK. Large increases in CPK have rarely been reported (se

Concomitant Therapy

In controlled clinical studies in which lovastatin was administered

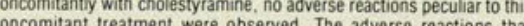
concomitant treatment were observed. The adverse reactions that occurred were limited to those reported previously with lovastatin or cho antly with lovastatip during controlled cline not administered concomiclinical studies, most of the patients who have developed myositis wer receiving concomitant therapy with immunosuppressive drugs or gem ibrozil (see WARNINGS. Skeletal Muscle)

Uncontrolled Clinical Studies

The adverse experiences observed in uncontrolled studies were similar to those seen in controlled clinical studies. Abnormal liver function tests were observed at a higher incidence than in the controlled studies (se elevations) was reported in approximately $0.5 \%$ of patients (see WARN INGS. Skeletal Muscle)

Causal Relationship Unclear

Nervous System: A single case of peripheral neuropathy has been reported: the relationship to lovastatin is uncertain. Visual evoked re sponse, nerve conduction measurements, and electromyography in over Specia/ Senses: Of 431 patients examined with slit lamp at baseline an during therapy with lovastatin, 34 had opacities reported at the fina exarination (5 to 15 months after stanting lovastatin) that were not noted at baseline. On the other hand, in 45 patients, opacities observed at baseline were not noted at the final examination, so that the prevalence did

$$
\text { OVERDOSAGE }
$$

. The oral LD S0 $_{0}$ of MEVACOR in mice is $20 \mathrm{~g} / \mathrm{kg}$.

\section{DOSAGE AND ADMINISTRATION}

The patient should be placed on a standard cholesterol-lowering diet before receiving MEVACOR and should continue on this diet during The recommended evening meal. The recommended dosing range is 20 to $80 \mathrm{mg} /$ day in single or divided doses; the maximum recommended dose is $80 \mathrm{mg} / \mathrm{day}$. Adjustments of dosage should be made at intervals of 4 weeks or more. Doses should be individualized according to the patient's response (see response results.

For those patients with severely elevated serum cholesterol levels (i.e. $300 \mathrm{mg} / \mathrm{dL}[7.8 \mathrm{mmol} / \mathrm{L}$ ] on diet). MEVACOR may be initiated at 40 mg/day. should be given to reducing the dosage of MEVACOR if cholesterol levels below the targeted range.

HOW SUPPLIED

Tablets MEVACOR $20 \mathrm{mg}$ are light blue, octagonal tablets, coded MSD 731 on one side and MEVACOR on the other. They are supplied in unit-of-use bottles of 60 and in unit-dose

MEACK

For more detailed information, consult your MSD Representative or see For more detailed information, consult your MSD Representative or see
Prescribing Information, Merck Sharp \& Dohme, Division of Merck \& Prescribing Information, Merck S
Co., INC., West Point, PA 19486. 
tube itself presents hygienic, esthetic, and social problems.

Surgery serves as an alternative, but only in rare cases where an anatomic malfunction can be found.

Moderate weight loss $(22 \mathrm{lb})$ can allieviate the problem in obese persons. However, long-term weight reduction proves difficult except for the highly motivated individual. Even then, dieters only have a $50 \%$ chance of experiencing relief.

Nasal continuous positive airway pressure uses a soft nasal mask strapped to the face with continuous air flowing through it. This device is both expensive and uncomfortable. Its long-term effectiveness has yet to be determined.

Uvulopalatopharyngoplasty, the removal of excess oropharyngeal tissue, restores pharyngeal patency during sleep. However, it is successful in reversing abnormal breathing only $50 \%$ of the time. Temporary nasal regurgitation is a minor complication.

While one treatment may benefit each person on an individual basis, uvulopalatopharyngoplasty seems to be the most promising option.

Gleeson K, Zwillich CW: Therapeutic approach to obstructive sleep apnea. Prac Cardiol 1987;13:55-63.

\section{Laser applications in surgery and medicine}

Lasers provide an attractive alternative to conventional therapy in many instances. Less blood loss and infection, precise cutting abilities, excellent visibility, hemostasis and vaporizing capabilities make it so.

Three different types of lasers to date have shown the most versatility: argon, carbon dioxide $\left(\mathrm{CO}_{2}\right)$, and neodymium:yttrium-aluminum-garnet (Nd:YAG).

Argon lasers have been used successfully for dermatologic and ophthalmologic procedures. However, they are bulky and the projected light is not effectively absorbed by most tissues.

Cutting or vaporizing lesions are best performed with the $\mathrm{CO}_{2}$ laser. This type features two operation modes, but power must be carefully controlled to prevent damage to sur- rounding tissues.

Nd:YAG provides the most versatility. It has many applications in ophthalmology, gastroenterology, and surgery. Its visible green light readily travels through fiber optics, making hard-to-reach areas easily accessible. The ability to penetrate tissue fluids makes this laser ideal for treating cancers of the urinary bladder.

Certain precautions must be taken when using lasers-proper release of fumes, a wet surrounding field, eye protection, and using nonflammable anesthetics.

Bohigian GM, Drake EH, Stellar, S: Laser applications today and tomorrow. Patient Care 1987;21:62-79.

\section{Minoxidil shows limited effectiveness for hair growth}

In a recent comparison study, oral minoxidil elicited more hair growth than topical minoxidil in treating alopecia areata. The former proved cosmetically effective in only $18 \%$ of participants.

Sixty-five volunteers ( 27 men and 38 women) took part in this study to determine the efficacy of oral minoxidil. Thirty-four had previously taken part in an earlier investigation in which $5 \%$ topical minoxidil provoked no or limited response. The patients ranged in age from 13 to 55 and had experienced hair loss for the last 1 to 26 years.

At baseline, $68 \%$ of the subjects exhibited $75 \%$ to $100 \%$ scalp hair loss. Nineteen persons had lost $25 \%$ to $74 \%$ of their hair, while two had lost $0 \%$ to $24 \%$.

Subjects were placed on a strict 2 g sodium diet in conjunction with oral minoxidil $(5 \mathrm{mg} / 12 \mathrm{hr}$ ). They were seen one month after baseline and every three months thereafter for a mean duration of 53 weeks. Scalp biopsies were performed at baseline and six months.

Fifty-two persons from the $75 \%$ to $100 \%$ hair loss group responded to the oral minoxidil. All those exhibiting less than $75 \%$ hair loss at baseline responded to the oral agent; $70 \%$ from the last group showed signs of regrowth.

Mean time to regrowth period ranged from 4 to 32 weeks; cosmetic regrowth occurred in 12 to 61 weeks.

Results from the earlier study of $5 \%$ topical minoxidil elicited regrowth in $47 \%, 29 \%$, and $3 \%$ of persons from each of the three respective baseline categories.

Neither form of minoxidil would significantly help most patients with alopecia areata even if the percutaneous absorption problem associated with topical applications was solved.

Fiedler-Weiss VC, Rumsfield J, Buys CM, et al: Evaluation of oral minoxidil in the treatment of alopecia areata. Arch Dermatol 1987;123:1488-1490.

\section{Antibiotics in biliary tract infections}

Researchers found piperacillin effective in treating persons with acute cholecystitis. Traditional antibiotic agents remain the treatment of choice for patients with cholangitis.

One-hundred six patients with biliary tract infections were involved in this prospective, randomized, 20 month trial of ampicillin and tobramycin, cefoperazone, and piperacillin. These antibiotics were administered for a minimum of five days.

Clinical cure rates for each of the 3 antibiotic regimens were $85 \%$, $95 \%$, and $95 \%$, respectively, for persons with acute cholecystitis. The same regimens faired less favorably in patients with cholangitis- $85 \%$, $56 \%$, and $60 \%$, respectively.

Investigators suggest penicillin and aminoglycosides should remain the standard therapies for cholangitic patients until more data are collected further verifying the efficacy of these newer antibiotics.

Muller EL, Pitt HA, Thompson JE Jr, et al Antibiotics in infections of the biliary tract Surg Gynecol Obstet 1987;165:285-292.

\section{Is TB screening needed for hospital employees?}

In a prospective study, hospital employees in institutions with tuberculosis (TB) patients did not convert at a statistically signficantly higher rate than their counterparts in nontuberculosis surroundings.

A three-year Washington state 


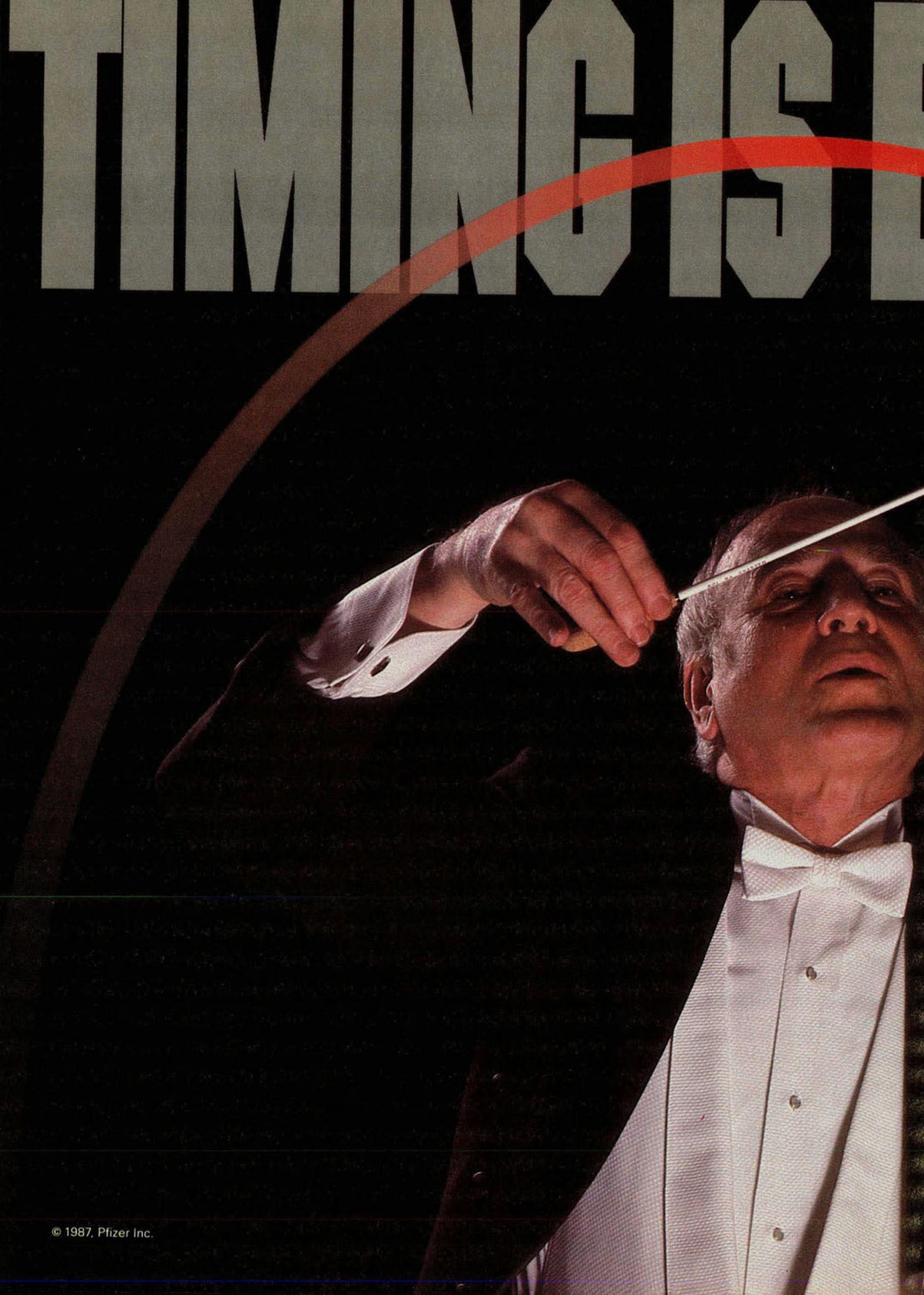


1. Sachs R. Frank M Fishman SK: Overview of clinical experience with glipizide. in Glipizide: A Worldwide Review. Princeton, NJ. Excerpta Medica. 1984, pD 163-172

\section{GLUCOTROL' (glipizide) Tablet:}

Brief Summary of Preseribing Information

INDICATIONS AND USAGE: GLUCOTROL is indicated as an adjunct to diet for the control of hyperglycemia in patients with non-insulin-dependent diabetes meliltus (NIDDM, type II) after an adequate trial of dietary therapy has proved unsatisfactory

CONTRAINOICATIONS: GLUCOTROL is contraindicated in patients with known hypersensitivity to the drug of with

diabetic ketoacidosis, with or without coma, which should be treated with insulin.
SPECIAL WARNING ON INCREASED RISK OF CARDIOVASCULAR MORTALITY: The administration of oral hypogly cemic drugs has been reported to be associated with increased cardiovascular mortality as compared to rreatment with diet alone or diet plus insulin. This warning is based on the study conducted by the University Group Diabetes Program (UGDP), a long-term prospective clinical trial designed to evaluate the effectiveness of glucose-lowering drugs in preventing or delaying vascular complications in patients with non-insulin-dependent diabetes. The study involved 823 patients who were randomly assigned to one of four treatment groups (Diabetes 19. supp. 2:747-830, 1970

UGDP reported that patients treated for 5 to 8 years with diet plus a fixed dose of tolbutamide (1.5 grams per day) had a rate of cardiovascular mortality approximately 2-1/2 times that of patients treated with diet alone. A significant increase in total mortality was not observed, but the use of tolbutamide was discontinued based on the increase in cardiovascular mortality, thus limiting the opportunity for the study to show an increase in overall mortality. Despite controversy regarding the interpretation of these results, the findings of the UGOP study provide an adequate basis for this warning. The patient should be informed of the potential risks and advantages of GLUCOTROL and of alternative modes of therapy.

Although only one drug in the sulfonylurea class (tolbutamide) was included in this study, it is prudent from a salety standpoint to consider that this warning may also apply to other oral hypoglycemic drugs in this class, in view of their close similarities in mode of action and chemical structure.

PRECAUTIONS: Renal and Hepatic Disease: The metabolism and excretion of GLUCOTROL may be slowed in patients with impaired renal and/or hepatic function. Hypoglycemia may be prolonged in such patients should it occur Hypoglycemia: All sultonylureas are capable of producing severe hypoglycemia. Proper patient selection, dosage and instructions are important to avoid hypoglycemia. Renal or hepatic insufficiency may increase the risk of hypoglycemic reactions. Elderily, debilitated, or mainourished patients and those with adrenal or pituitary insufficiency are particularly susceptible to the hypoglycemic action of glucose-lowering drugs. Hypoglycemia may be difficult to recognize in the elderly or people taking beta-adrenergic blocking drugs. Hypoglycemia is more likely to occur when caloric intake is deficient, after severe or prolonged exercise, when alcohol is ingested. or when more than one glucose-lowering ofrug is used

Loss of Control of Blood Glucose: A loss of control may occur in diabetic patients exposed to stress such as fever. trauma. infection or surgery. It may then be necessary to discontinue GLUCOTROL and administer insulin. Laboratory Tests: Blood and urine glucose should be monitored periodically Measurement of glycosylated hemo. globin may be useful.

Information for Patients: Patients should be informed of the potential risks and advantages of GLUCOTROL. of alternative modes of therapy. as well as the importance of achering to dietary instructions, of a regular exercise program, and of regular testing of urine and or blood glucose. The risks of hypoglycemia, its symptoms and treatment, and conditions that predispose to its development should be explained to patients and responsible family members. Primary and secondary fallure should also be explainec.

Orug Interactions: The hypoglycemic action of sultonylureas may be potentiated by certain drugs including nonsteroidal anti-inflammatory agents and other drugs that are highly protein bound, salicylates. sulfonamides. chloramphenicol, probenecid, coumarins, monoamine oxidase inhibitors, and beta adrenergic blocking agents. in vitro studies indicate that GLUCOTROL binds differently than tolbutamide and does not interact with salicylate or dicumarol. However, caution must be exercised in extrapolating these findings to a clinical situation. Certain drugs tend to produce hyperglycemia and may lead to loss of control, including the thiazides and other diuretics. corticosteroids. phenothiazines, thyroid products, estrogens, oral contraceptives. phenytoin, nicotinic acid, sympathomimetics, calcium channel blocking drugs, and isoniazid. A potential interaction between oral miconazole and oral hypoglycemic agents leading to severe hypoglycemia has been reported. Whether this interaction also occurs with the intravenous, topical, or vaginal preparations of miconazole is not known.

Carcinogenesis, Mutagenesis, Impairment of Fertility: A 20-month study in rats and an 18-month study in mice at doses up to 75 times the maximum human dose revealed no evidence of drug-related carcinogenicity. Bacterial and in vivo mutagenicity tests were uniformly negative. Studies in rats of both sexes at doses up to 75 times the human dose showed no effects on fertility

Pregnancy: Pregnancy Category C. GLUCOTROL (glipizide) was found to be mildly fetotoxic in rat reproductive studies at all dose levels $(5-50 \mathrm{mg} / \mathrm{kg})$. This fetotoxicity has been similarly noted with other sultonylureas, such as tolbutamide and tolazamide. The effect is perinatal and believed to be directly related to the pharmacologic (hypoglycemic) action of GLUCOTROL. In studies in rats and rabbits no teratogenic effects were found. There are no adequate and well-controlled studies in pregnant women. GLUCOTROL should be used during pregnancy only if the potential benefit justifies the potential risk to the fetus.

Because recent information suggests that abnormal blood glucose levels during pregnancy are associated with higher incidence of congenital abnormalities. many experts recommend that insulin be used during pregnancy to maintain blood glucose levels as close to normal as possible.

Nonteratogenic Effects: Prolonged severe hypoglycemia has been reported in neonates born to mothers who were receiving a sulfonylurea drug at the time of delivery. This has been reported more frequently with the use of agents with prolonged hall-lives. GLUCOTROL should be discontinued at least one month before the expected delivery date. Nursing Mothers: Since some sulfonylurea drugs are known to be excreted in human milk, insulin therapy should be considered if nursing is to be continued

Pediatric Use: Satety and effectiveness in children have not been established

ADVERSE REACTIONS: In controlled studies, the frequency of serious adverse reactions reported was very low. 0 702 patients, $11.8 \%$ reported adverse reactions and in only $1.5 \%$ was GLUCOTROL discontinued

Hypoglycemia: SEe PRECAUTIONS and OVERDOSAGE sections.

Gastrointestinal: Gastrointestinal disturbances, the most common, were reported with the following approximate incidence: nausea and diarrhea, one in 70. constipation and gastralgia, one in 100 . They appear to be dose-related and may disappear on division or reduction of dosage. Cholestatic janndice may occur rarely with sultonylureas: GLUCOTROL should be discontinued if this occurs

Dermatologic: Allergic skin reactions including erythema, morbilliform or maculopapular eruptions, urticaria, pruritus. and eczema have been reported in about one in 70 patients. These may be transient and may disappear despite continued use of GLUCOTROL: if skin reactions persist. the drug should be discontinued. Porphyria cutane larda and photosensitivity reactions have been reported with sulfonylureas

Hematologic: Leukopenia, agranulocytosis, thrombocytopenia, hemolytic anemia, aplastic anemia, and pan cytopenia have been reported with sulfonylureas

Metabolic: Hepatic porphyria and disulfiram-like alcohol reactions have been reported with sulfonylureas. Clinical experience to date has shown that GLUCOTROL has an extremely low incidence of disulfiram-like reactions. Endocrine Reactions: Cases of hyponatremia and the syndrome of inappropriate antidiuretic hormone (SIADH) secretion have been reported with this and other sulfonylureas.

Miscellaneous: Dizziness, drowsiness. and headache have each been reported in about one in fifty patients treated with GLUCOTROL. They are usually transient and seldom require discontinuance of therapy

OVERDOSAGE: Overdosage of sulfonylureas including GLUCOTROL can produce hypoglycemia. If hypoglycemic coma is diagnosed or suspected. the patient should be given a rapid intravenous injection of concentrated $(50 \%)$ glucose solution. This should be followed by a continuous infusion of a more dilute $(10 \%)$ glucose solution at rate that will maintain the blood glucose at a level above $100 \mathrm{mg}$ dL. Patients should be closely monitored for a minimum of 24 to 48 hours since hypoglycemia may recur after apparent clinical recovery Clearance of GLUCOTROL from plasma would be prolonged in persons with tiver disease. Because of the extensive protein binding of GLUCOTROL (glipizide). dialysis is unlikely to be of benefi.

DOSAGE AND ADMIMISTAATION: There is no fixed dosage regimen for the management of diabetes mellitus with GLUCOTROL; in general, it should be given approximately 30 minutes before a meal to achieve the greatest reduction in postprandial hyperglycemia.

Initial Dose: The recommended starting dose is $5 \mathrm{mg}$ before breaktast. Geriatric patients or those with liver disease may be started on $2.5 \mathrm{mg}$. Dosage adjustments should ordinarily be in increments of $2.5-5 \mathrm{mg}$. as determined by blood glucose response. At least several days should elapse between titration steps

Maximum Dose: The maximum recommended total daily dose is $40 \mathrm{mg}$

Maintenance: Some patients may be effectively controlled on a once-a-day regimen, while others show better response with divided dosing. Total daily doses above $15 \mathrm{mg}$ should ordinarily be divided.

HOW SUPPLIED: GLUCOTROL is avalable as white, dye-free, scored diamond-shaped tablets imprinted as follows $5 \mathrm{mg}$ tablet-Pfizer 411 (NDC $5 \mathrm{mg}$ 0049-4110-66) Bottles of 100; $10 \mathrm{mg}$ tablet - Pfizer 412 (NDC $10 \mathrm{mg} 0049-4120-66$ ) Botties of 100

CAUTION: Federal law prohibits dispensing without prescription study of 114 hospitals monitored the skin tests of $13.7 \%$ to $100 \%$ of employees. Of this number, 129 were true converters. Employee conversion rates were higher in larger hospitals than small.

Considering that only $1 / 30$ of converters may actually develop active tuberculosis, 3 persons during the entire investigation would have benefited from taking the recommended therapeutic agent. Based on this projection, the authors suggest two-step skin testing be performed upon employment and thereafter only in cases of TB patient contact.

Aitken ML, Anderson KM, Albert RK: Is the tuberculosis screening program of hospital employees still required? Am Rev Respir Dis 1987;136:805-807.

\section{Abnormal glucose tolerance and risk of coronary artery disease}

Hyperinsulinemia, hypercholesterolemia, and hypertriglyceridemia were found in nondiabetic persons with abnormal oral glucose tolerance. These persons also exhibited signficantly higher systolic blood pressure and heart rates.

Seven-hundred thirty-two volunteers participated in a health survey. Of these, 50 were diagnosed as having impaired glucose tolerance. Fifty persons with normal glucose tolerance also were identified for comparison purposes. The latter matched as close as possible in weight, sex, height, and age to their glucose-impaired counterparts.

As earlier studies contradict these findings, the causal relationship between multiple metabolic and hemodynamic changes and the risk of coronary artery disease has yet to be established.

Zavaroni I, Dall'Aglio E, Bonora E, et al: Evidence that multiple risk factors for coronary artery disease exist in persons with abnormal glucose tolerance. Am J Med 1987;83:609-612. 


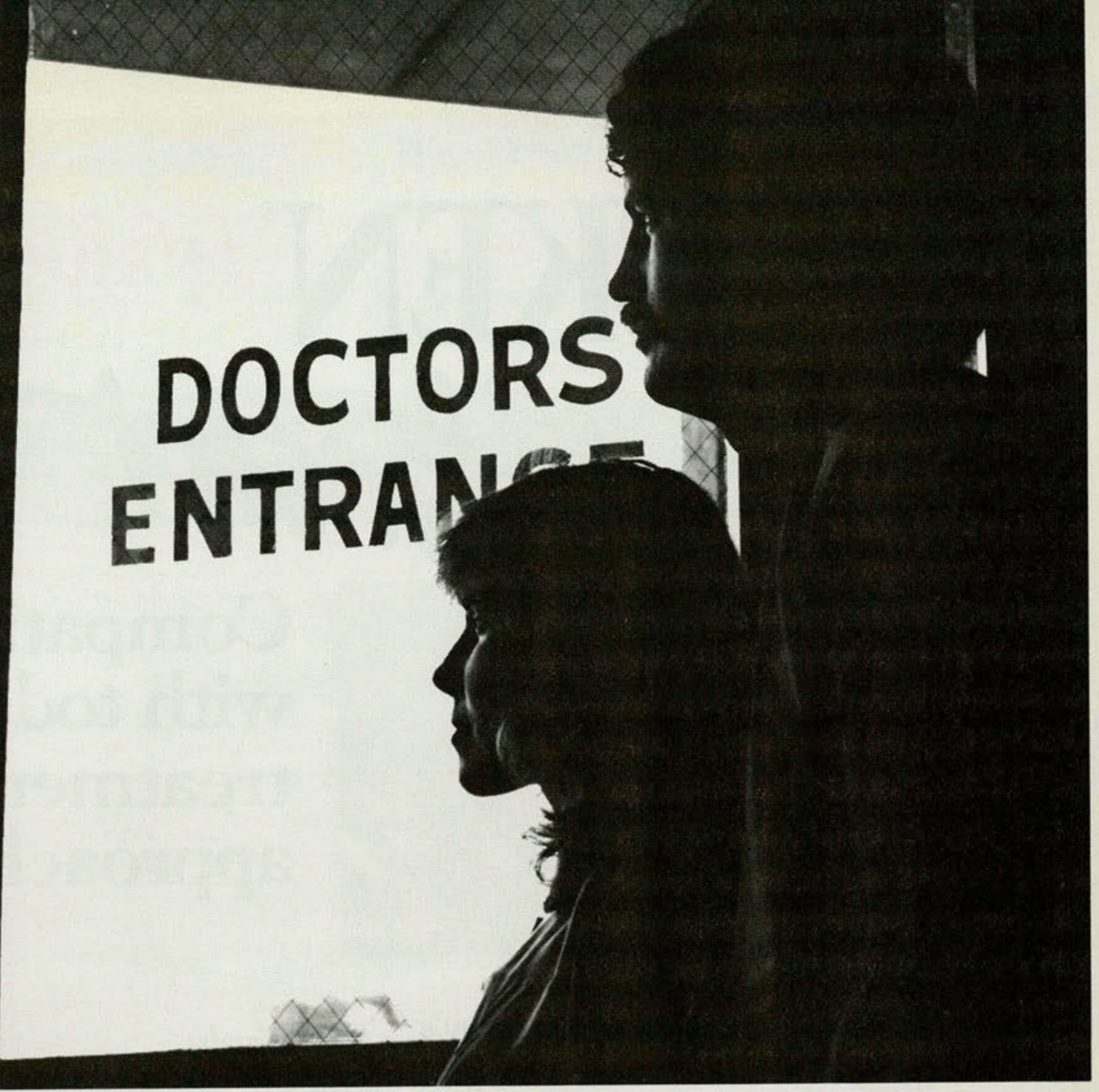

\section{Education ... that's} what it's all about at Flint Ostebe, acute and general care.

\begin{tabular}{ll}
\hline Residencies & Fellowships \\
\hline - Anesthesia & - Medical Diseases of the \\
- Family Practice & Chest \\
- Gastroenterology & - Gastroenterology
\end{tabular}

- Internal Medicine

- Obstetrics/Gynecology

- Ophthalmology

- Orthopedics

- Pathology

- Pulmonary

- Radiology

- Surgery

- Urology
One-year rotating internships

Student externships

Monthly Congdon lecture series

Daily guest lectures छ Morning reports

Journal Clubs
Christopher T. Meyer, D.O.

Vice President of Medical

Education

Dennis V. DeSimone, D.O.

Director of Medical

Education

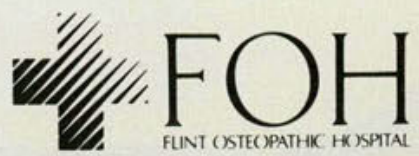

(313) 762-4707 
In managing hypertension take a N $\mathrm{kW}$ look
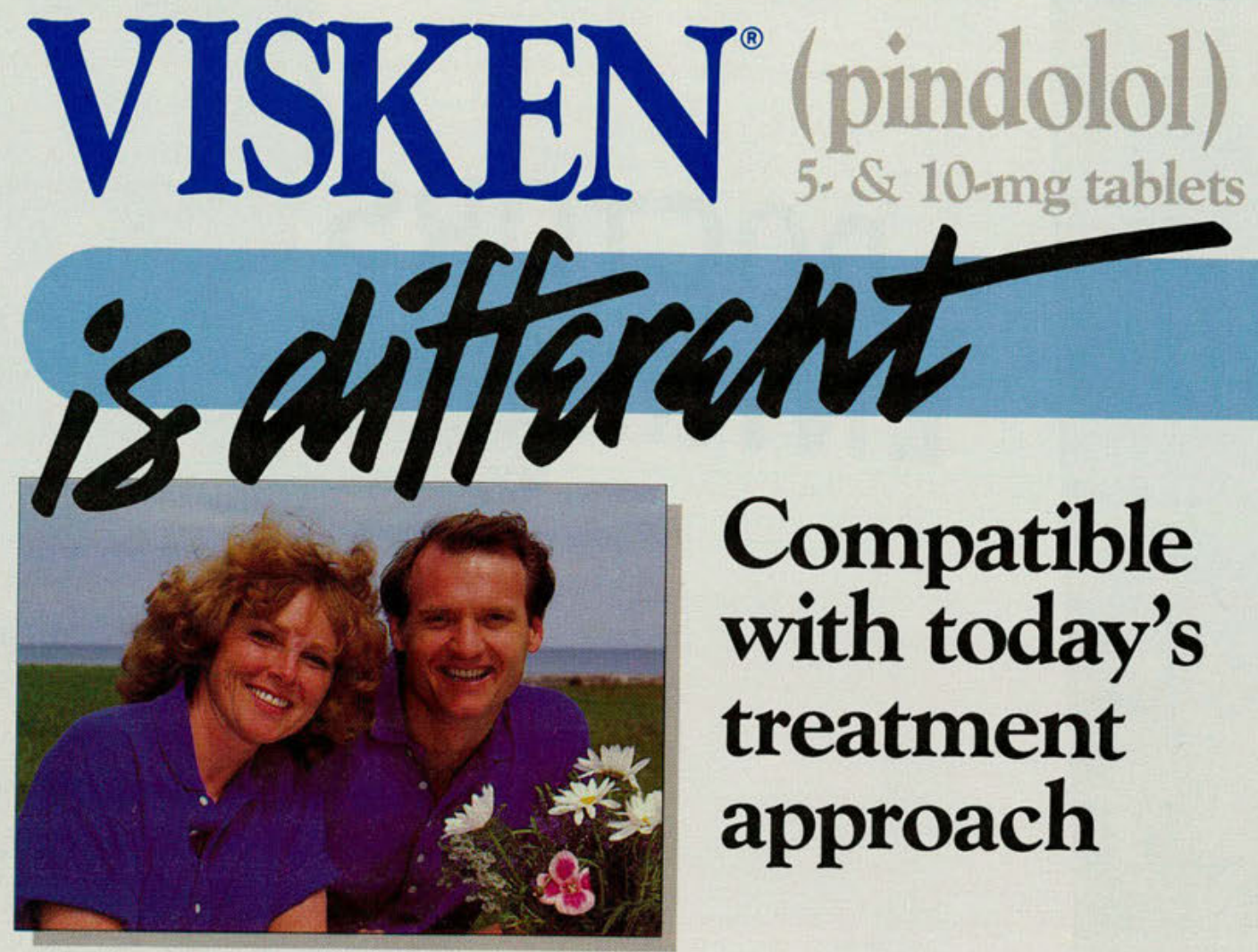

Meets today's efficacy goals regardless of age $^{1}$ blood pressure ${ }^{2}$

Allows patients to participate in healthy exercise

Offers a due to minimal fatigue $^{2}$

Effectively lowers

low side effect profile $^{2}$

Supports the low-cholesterol diet

\section{Plus}

you

Visken $^{\circ}$ (pindolol)

has a favorable recommend lipid profile 
Changes in the lipid profile* after initiating beta blockers

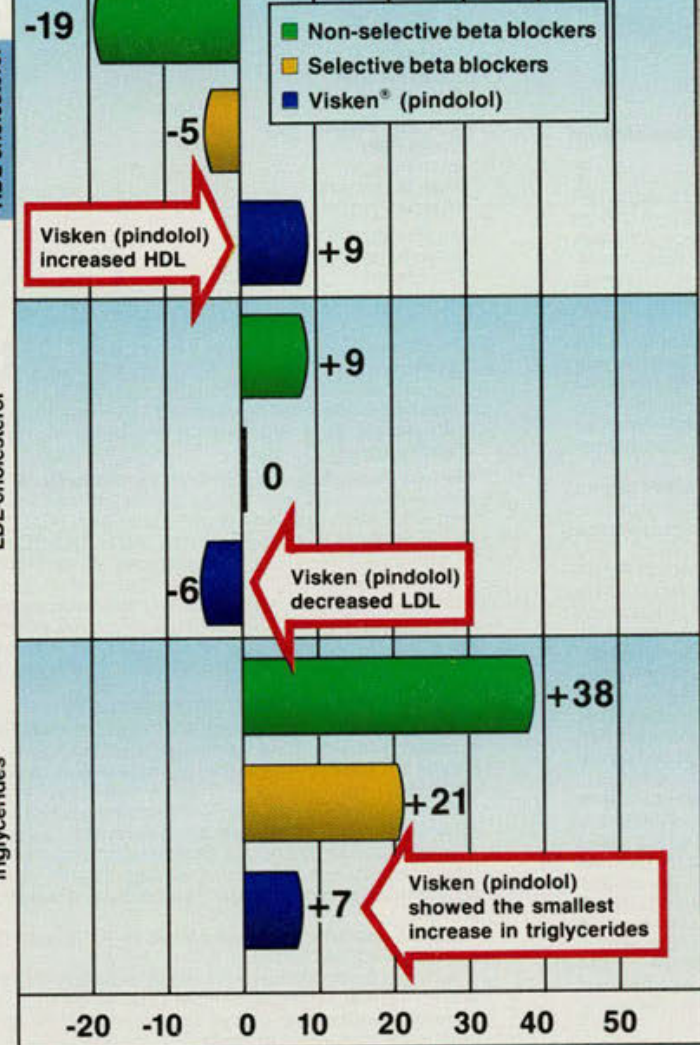

Adapted from van Brummelen, J Cardiovasc Pharmacol 1983;5(suppl. 1):S51-S55.

- None of the marketed $\beta$-blockers significantly affected the total cholesterol plasma concentration.

Standard Deviations:

Non-selective beta blockers:

HDL $-19 \pm 7 \quad$ LDL $+9 \pm 20 \quad$ Triglycerides $+38 \pm 24$

Selective beta blockers:

$\mathrm{HDL}-5 \pm 7 \quad$ LDL $0 \pm 5 \quad$ Triglycerides $+21 \pm 19$

Pindolol:

HDL $+9 \pm 9$ LDL $-6 \pm 2 \quad$ Triglycerides $+7 \pm 14$

\section{The difference} is lipids in hypertension

Visken therapy offers both effective reduction of blood pressure and a favorable lipid profile, which help to reduce certain risk factors. ${ }^{3}$ Unlike non-selective and cardioselective beta blockers, Visken (pindolol) increased HDL and lowered LDL in separate studies* ${ }^{3}$ Visken (pindolol) also exhibited the smallest increase in triglycerides of all the beta blockers tested. ${ }^{3}$

"Data are based on a review of a number of studies, analyzing the results separately for each of the three major classes of beta blockers.

This chart shows mean percentage changes $( \pm S D)$ in plasma triglycerides, low-density lipoprotein (LDL)-cholesterol and highdensity lipoprotein (HDL)-cholesterol during treatment with $\beta$-blockers.

Visken (pindolol) is indicated in the treatment of hypertension. ${ }^{5}$ It is not a cholesterol lowering agent and is not indicated for the treatment of hyperlipidemia.

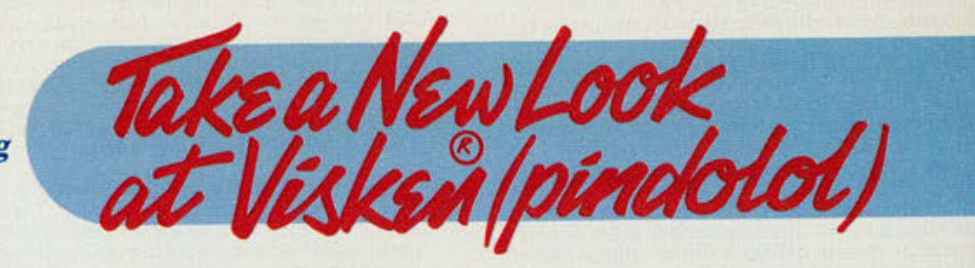


1. Marks AD, Finestone A, Sobel E, et al: An office-based primary care trial of pindolol ("Visken") in essential hypertension. Curr Med Res Opin 1986;10:296-307. Corporation.

3. van Brummelen P: The relevance of intrinsic sympatho mimetic activity for $\beta$-blocker-induced changes in plasma lipids. JCardiovasc Pharmacol 1983;5(suppl.1): S51-S55. 4. Lehtonen A: Long-term effect of pindolol on plasma lipids, apoproteins A, blood glucose, and serum in. 22:269-272.

5. Physicians' Desk Reference, ed. 41, Oradell, New Jersey, Medical Economics Co., 1987, pp. 1794-1796.

\section{VISKEN ${ }^{\circ}$}

\section{(pindolol) tablets, USP}

CAUTION:Federal law prohibits dispensing without prescription.

Before prescribing or administering, see package circular Pull product information.

The following is a brief summary

\section{INDICATIONS AND USAGES}

Visken" (pindolol) is indicated in the management of hypertension. It may be used alone or concomitantly with other antihypertensive agents, particularly with a thiazide type diuretic

\section{CONTRAINDICATIONS}

Visken (pindolol) is contraindicated in: 1) bronchial asthma 2) overt cardiac failure; 3) cardiogenic shock; 4) second and third degree heart block; 5) severe bradycardia; (see Warnings).

\section{WARNINGS}

Cardiac Failure: Sympathetic stimulation may be a vital circulatory function in patients with in mayprecipitatem should be avoided in overt congestive heartfailure, if necessary, Visken (pindolol) can be used with caution in patients with a history of failure who are well-compensated, usually with digitalis and diuretics. Beta-adrenergic blocking agents muscle.

In Patients Without A History of Cardiac Failure: In patients with latent cardiac insufficiency, continued depression of the myocardium with beta-blocking agents over a period of time can in some cases lead to cardiac failure. patients sign or symptom of impending cardiac failure, uretic, and the response observed closely. If cardiac failure Visken (pindolol) therapy should be withdrawn (gradually if possible).

of Ischemic Heart Disease Following Abrupt Withdrawal: Hypersensitivity to catecholamines has been observed in patients withdrawn from beta-blocker therapy; exacerbation of angina and, in some cases, myocardial infarction have occurred after abrupt discontinuation of such therapy. When discontinuing chronically administered Visken (pindolol), particularly in patients with ischemic heart disease, the dosage should be gradually reduced over a period of one to two weeks and the patient should be carefully monitored. If angina markedly worsens or acute coronary insufficiency develops, Visken (pindolol) administration should be reinstituted promptly, at least temporarily, and other measures appropriate for the management of unstable angina should be taken. Patients should be warned against interruption or discontinuation of therapy without the physician's advice. Because coronary arterydisease is common and maybe unrecognized, it may abruptly even in patients treated only for hypertension.

Nonallergic Bronchospasm (e.g., chronic bronchitis, emphysema)-Patients with Bronchospastic Diseases Should in General Not Receive Beta-Blockers: Visken (pindolol) should be administered with caution since it may blockbronchodilation produced byendogenousorexogenous catecholamine stimulation of beta receptors.

Major Surgery: Because betablockade impairs the ability of the heart to respond to reflex stimuliand may increase th risks of general anesthesia and surgical procedures, re sulting in protracted hypotension or low cardiac output it has generallybeen suggested that such therapyshould be with drawn several days prior to surgery. Recognition of the in creased sensitivity to catecholamines of patients recently withdrawn from beta-blocker therapy however has this recommendation controversial. If possible, beta blockers should be withdrawn well before surgery takes place. In the event of emergency surgery, the anesthesiol ogist should be informed that the patient is on beta blocker therapy.

The effects of Visken (pindolol) can be reversed by administration of beta-receptor agonists such as isoprotereno, dopamine, dobutamine, or levarterenol. Difficulty in restarting and maintaining the heart beat has also been re ported with beta-adrenergic receptor blocking agents.

Diabetes and Hypoglycemia: Beta-adrenergic blockade may prevent the appearance of premonitory signs and symptoms (e.g., tachycardia and blood pressure changes) of acute hypoglycemia. This is especially important with labilediabetics. Beta-blockadealso reduces the release of insulin in response to hyperglycemia; therefore, it may be necessary to adjust the dose of antidiabetic drugs. Thyrotoxicosis: Beta-adrenergic blockade may mask certain clinical signs (e.g., tachycardia) of hyperthyroidism. managed carefully to avoid abrupt withdrawal of betablockade which might precipitate a thyroid crisis.

\section{PRECAUTIONS}

Impaired Renal or Hepatic Function: Beta-blocking agents should be used with caution in patients with impaired hepatic or renalfunction. Poor renal function has only minor effects on Visken" (pindolol) clearance, but poor hepatic

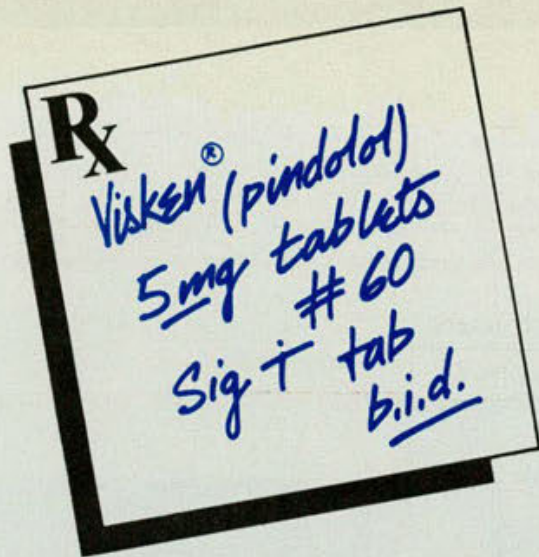

function may cause blood levels of Visken* (pindolol) to increase substantially.

Information for Patients: Patients, especially those with evidence of coronary artery insufficiency, should be warned against interruption or discontinuation of Visken (pindolol) therapy without the physician's advice. Although cardiac failure rarely occurs in properly selected patients, patients being treated with beta-adrenergic blocking agents
should be advised to consult the physician at the first sign

or symptom of impending failure.

Drug Interactions: Catecholamine-depleting drugs (e.g., reserpine) may have an additive effect when given with beta-blocking agents. Patients receiving Visken (pindolol) plus a catecholamine depleting agent should, therefore, be closely observed for evidence of hypotension and/or marked bradycardia which may produce vertigo, syncope, or posural hypotension.

Visken (pindolol) has been used with a variety of antihypertensive agents, including hydrochlorothiazide, hydralazine, and guanethidine without unexpected adverse interactions.

Carcinogenesis, Mutagenesis, Impairment of Fertility: In chronic oral toxicologic studies (one to two years) in mice, rats, and dogs, Visken (pindolol) did not produce an significant toxic effects. In two-year oral carcinogenicity studies in rats and mice in doses as high as $59 \mathrm{mg} / \mathrm{kg} / \mathrm{day}$ and $124 \mathrm{mg} / \mathrm{kg} / \mathrm{day}$ (50 and 100 times the maximum recommended humandose), respectively, Visken (pindolol)didno produce any neoplastic, preneoplastic, or nonneoplastic pathologic lesions. In fertility and general reproductive performance studies in rats, Visken (pindolol) caused no adverse effects at a dose of $10 \mathrm{mg} / \mathrm{kg}$.

In the male fertility and general reproductive performance test in rats, definite toxicity characterized by mortality and decreased weight gain was observed in the group given $100 \mathrm{mg} / \mathrm{kg} /$ day. At $30 \mathrm{mg} / \mathrm{kg} /$ day, decreased mating was associated with testicular atrophy and/or decreased spermatogenesis. This response is notclearlydrug related, however, as there was nodose response relationship within this experiment and no similar effecton testes of ratsadmin istered Visken (pindolol) as a dietary admixture for 104 weeks. There appeared to be an increase in prenatal mortality in males given $100 \mathrm{mg} / \mathrm{kg}$ but development of offspring was not impaired.

In females administered Visken (pindolol) prior to mating through day 21 of lactation, mating behavior was decreased at $100 \mathrm{mg} / \mathrm{kg}$ and $30 \mathrm{mg} / \mathrm{kg}$. At these dosages there alsowas increased mortality of offspring. Prenatal mortality was increased at $10 \mathrm{mg} / \mathrm{kg}$ but there was not a clear dose response relationship in this experiment. There was an increased resorption rate at $100 \mathrm{mg} / \mathrm{kg}$ observed in females necrop. sied on the 15th day of gestation.

Pregnancy -Category B: Studies in rats and rabbits ex. ceeding 100 times the maximum recommended human doses, revealed noembryotoxicity or teratogenicity. Since there are no adequate and well-controlled studies in preg. nant women, and since animal reproduction studies are not always predictive of human response, Visken (pindolol), as with any drug should be employed during pregnancyonly if the potential benefitjustifies the potential risk to the fetus. Nursing Mothers: Since Visken (pindolol) is secreted in human milk, nursing should not be undertaken by mothers receiving the drug.

Pediatric Use: Safety andeffectiveness in children have not been established.

\section{CLINICAL LABORATORY}

Minor persistentelevationsinserumtransaminases(SGOT, SGPT) have been noted in $7 \%$ of patients during Visken (pindolol) administration, but progressive elevations were not observed and liver injury has not been reported in the medical literature over a ten ( 10 ) year period of marketing. Alkaline phosphatase, lactic acid dehydrogenase $(\mathrm{LDH})$ and uric acid are also elevated on rare occasions. The significance of these findings is unknown.

\section{ADVERSE REACTIONS}

Most adverse reactions have been mild. The incidences listed in the following table are derived from 12-week comparative double-blind, parallel design trials in hypertensive patients given Visken (pindolol) as monotherapy, given various active control drugs as monotherapy, or given placebo. Data for Visken (pindolol) and the positive controls were pooled from several trials because no striking diferences were seen in the individual studies, with one exceprequency of edema was noticeably higher in positive, the trol trials [ $16 \%$ Visken (pindolol) vs. $9 \%$ positive control] than in placebo controlled trials $16 \%$ Visken (pindolol) vs. $3 \%$ placebo]. The table includes adverse reactions vither placebo]. The table includes adverse reactions either volunteered or elicited, and at least possibly drug related, patients and other selected important reactions.

Adverse Reactions which were Volunteered or Elicited (and at least possibly drug related)

\begin{tabular}{cccc}
$\begin{array}{c}\text { Body System/ } \\
\text { Adverse } \\
\text { Reactions }\end{array}$ & $\begin{array}{c}\text { Visken } \\
\text { (pindolol) } \\
(\mathrm{N}=322) \\
\%\end{array}$ & $\begin{array}{c}\text { Active } \\
\text { Controls } \\
(\mathrm{N}=188) \\
\%\end{array}$ & $\begin{array}{c}\text { Placeb } \\
(\mathrm{N}=78\end{array}$ \\
\hline
\end{tabular}

Central

Nervous System

Many Dream

Dizziness

Hallucinations

Insomnia

Nervousness

Autonomic

Nervous System

Cardiovascular

Dyspnea

Heart Failure

Palpitations

Musculoskeletal

Chest Pain

Joint Pain

Muscle Cramps

Muscle Pain

Gastrointestina

Abdominal

Nausea

Skin

Pruritus
Rash

- Active Controls: Patients received either propranolol, $\alpha$ methyldopa or a diuretic (hydrochlorothiazide or chlorthalidone).

The following selected (potentiallyimportant) adverse reacVOUS SYSTE (pindolol) is uncertain. CENTRAL NERVOUS SYSTEM: visual disturgy, AUTONOML NERCARDIOVASCULAR: remities, heart TINTINAL diape, tachycardia, weight gain; GASTROINTESTINAL: diarrhea, vomiting: pollakiuria; MISCELLANEOUS: eye discomfort or burning

\section{POTENTIAL ADVERSE EFFECTS}

In addition, other adverse effects not listed above have been reported with other beta-adrenergic blocking agents and should be considered potential adverse effects of Visken (pindolol)

Central Nervous System: Reversiblemental depression characterized by disorientation for time and place, short . sensorium, and decreased performance on neuropsychometrics.

Cardiovascular: Intensification of AV block. (See (

Allergic: Erythematous rash; fever combined with aching and sore throat; laryngospasm; respiratory distress.

Hematologic: Agranulocytosis; thrombocytopenicand nonthrombocytopenic purpura.

Gastrointestinal: Mesenteric arterial thrombosis: ischemic colitis.

Miscellaneous: Reversible alopecia: Peyronie's disease.

The oculomucocutaneous syndrome associated with the beta-blocker practolol has not been reported with Visker (pindolol) during investigational use and extensive foreig amounting to over 4 million patient-years. OVERDOSAGE

No specific information on emergency treatment of ove dosage is available. Therefore, on the basis of the pharmacologic actions of Visken (pindolol), the following general measures shoul

gastric lavage:

Excessive Bradycardia: administer atropine; if there is cautiously.

Cardiac Failure: digitalize the patient and/or administer diuretic. It has been reported that glucagon may be useful in this situation.

Hypotension: administer vasopressors, e.g., epine phrine or levarterenol, with serial monitoring of blood pres-
sure. (There is evidence that epinephrine may be the drug sure. (There
of choice.)

Bronchospasm: administer a heta timuting agent such as isoproterenol and/or a theophylline derivative. A case of an acute overdosage has been reported with a intake of $500 \mathrm{mg}$ of Visken (pindolol) by a hypertensive pa heart rate was $>80$ beat $/ \mathrm{min}$. Recovery was uneventful. In another case, 250 $\mathrm{mg}$ of Visken (pindolol) was taken with $150 \mathrm{mg}$ diazepam and 